\title{
OPTIMAL BLENDING QUALITY
}

By

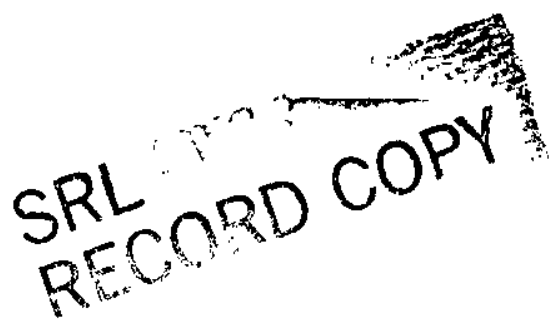

S. P. HARRIS

Scientific Computations Division

Publication Date: July, 1986

E. 1. du Pont de Nemours \& Co. Savannah River Laboratory Aiken, SC 29808 
This document was prepared in conjunction with work accomplished under Contract No.

DE-AC09-76SR00001 with the U.S. Department of Energy.

\section{DISCLAIMER}

This report was prepared as an account of work sponsored by an agency of the United States Government. Neither the United States Government nor any agency thereof, nor any of their employees, makes any warranty, express or implied, or assumes any legal liability or responsibility for the accuracy, completeness, or usefulness of any information, apparatus, product or process disclosed, or represents that its use would not infringe privately owned rights. Reference herein to any specific commercial product, process or service by trade name, trademark, manufacturer, or otherwise does not necessarily constitute or imply its endorsement, recommendation, or favoring by the United States Government or any agency

thereof. The views and opinions of authors expressed herein do not necessarily state or reflect those of the United States Government or any agency thereof.

This report has been reproduced directly from the best available copy.

Available for sale to the public, in paper, from: U.S. Department of Commerce, National Technical Information Service, 5285 Port Royal Road, Springfield, VA 22161, phone: (800)

553-6847, fax: (703) 605-6900, email: orders@ntis.fedworld.gov online ordering: http://www.ntis.gov/ordering.htm

Available electronically at http://www.doe.gov/bridge

Available for a processing fee to U.S. Department of Energy and its contractors, in paper, from: U.S. Department of Energy, Office of Scientific and Technical Information, P.O. Box 62, Oak Ridge, TN 37831-0062, phone: (865 ) 576-8401, fax: (865) 576-5728, email: reports@ adonis.osti.gov 


\section{Problem Statement}

The purpose of blending is to form an optimum quality lot from components with known quality attributes. In this application, the components are of the same material but may vary in quality because of process variability.

The product in the lot must satisfy its specifications which are usually tighter than component specifications. Also, the amount of product in the lot must be between 30 to 40 units while the amount in component containers varies between 2.5 to 10 units. When containers are selected for blending, their entire contents must be used. Multiple quality attributes are determined for each container from laboratory analyses.

\section{Summary}

We have developed a functional program for product blending. The program is installed at an SRP production site on their VAX computer. A wide range of blending choices is available. The program can be easily changed or expanded. The technology can be applied at other areas where mixing or blending is done.

Our blending strategy optimizes product quality for productions' special needs. Blends which reduce the amount of product sent to scrap recovery can be formed. At other times, a top quality lot may be needed for the customer to demonstrate the production of a quality product.

A top quality lot may be defined as the blend closest to target or in terms of a trade-off between closeness to target and product uniformity. The program provides choices for either definition.

The blending algorithm is based on using-Taguchi quadratic loss functions (Kackar,1985) to develop a quality index from multiple quality attributes. The average component quality index and the quality index, determined from the lot attributes, are then used to calculate a performance statistic. The performance statistic is used, to rank potential lots in meeting the blending strategy.

Kackar, R.N., Toctober 1985). Off-Line Quality Control, Parameter Design, and the Taguchi Method. Journal of Quality Technology. 
OPTIMAL BIENDING QUATITY

\section{Introduction}

The utility of blending is apparent for complex processes where it is difficult or cost prohibitive to eliminate rework. The blending strategies are not intended to be a substitute for this goal.

As the process improves through statistical process control procedures and use of experimental design methods, the need for blending should diminish.

\section{Strategies}

Several product blending strategies are considered. Other strategies may also be appropriate.

* Blend closest to target making optimal use of product near specification boundaries. (Blending from tails)

This strategy loosely defines a trade-off between closeness to target and blend variability. The objective is to arrive at a lot close to target (ideal values) using product at opposite sides of the target. For example, suppose the specification for an attribute is to be between 88 and 96 and the target is 92 . We wish to blend product close to 88 with product close to 96 in arriving at a lot near the target 92. Even though blending is easy to conceptualize for one attribute, it becomes a complex problem when considering several attributes. A benefit of the strategy is the product remaining in storage should have lower variability and be closer to target, thus making formation of new lots easier.

** Blend closest to target without regard to product variability. (Center Blending)

How close to target can we come for a blend when considering multiple quality attributes (e. g., weight percentages of certain materials, densities)? The strategy is more general than blending from tails. It can provide a benchmark for comparison with other strategies.

*** Blend with near minimum product variability with consideration of the target. (Uniform Blending)

Sometimes it may be desirable to form a blend with very low variability and also be near the target. For example, with a new product, the lot may be examined very closely by the customer. Therefore, we would want to maximize the probability of finding acceptable - quality characteristics for resampling. Consideration of the target is necessary since it is possible to have a blend with low variability near the specification boundaries, even though it may not be very likely. 
OPTIMAL BLENDING QUALITY

\section{Background Information}

Product is stored in 2-liter containers in a vault with maximum storage of 36 containers. Each container will be filled with varying amounts of product $(2.5$ to 10.0 units).

The objective is to form a blend having 30 to 40 units while meeting certain quality objectives.

The plant lab will produce estimates of four quality attributes from samples taken from each container. The data are stored in the Accountability system on their VAX computer. Each data record will contain a container/product identification number, the amount of product and the laboratory quality attribute values.

Only containers meeting specifications are used in the blending routine. The container and blend specifications are given in Table 1.

\section{Table 1}

\section{PRODUCT SPECIFICATIONS}

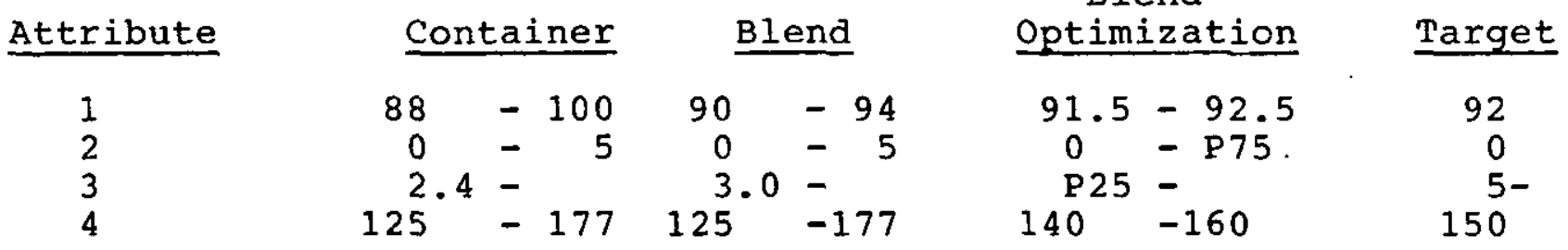

(P25\& P75 are the 25 th and 75 th attribute percentiles, respectively)

Container and blend specifications are set by the customer. The blend-optimization specifications were determined by us and the plant Quality control group with the aim of providing a cushion if the blend is resampled by the customer. Notice that they are tighter than the other specifications.

Some quality attributes are more important than others to the production group. Thus, they are prioritized as 408 , $25 \%, 25 \%$, and $10 \%$ for attributes $1,2,3$, and 4, respectively. The priority reflects the relative importance of the attribute. For example, attribute 1 is the most important. It is considered to be four times as important as attribute 4. Attributes 2 and 3 are considered equally important. 


\section{Blend Quality Attributes}

Quality attributes are estimated numerically for a potential blend from the container attributes measured by the Lab. A weighted average of the container attributes is used. The weights are the amount of product in the containers.

For example, consider attribute 1. Suppose containers 1, 2, 3 , and 4 are used to form a potential blend. Also, suppose the attributes and units are as follows:

\begin{tabular}{|c|c|c|c|c|c|}
\hline & \multicolumn{5}{|c|}{ Container } \\
\hline & $\underline{1}$ & $\underline{2}$ & $\underline{3}$ & $\underline{4}$ & Blend \\
\hline $\begin{array}{l}\text { Attribute } 1 \\
\text { Units }\end{array}$ & $\begin{array}{l}90.8 \\
10\end{array}$ & $\begin{array}{c}94.7 \\
7\end{array}$ & $\begin{array}{c}93.2 \\
9\end{array}$ & $\frac{91.7}{5}$ & $\begin{array}{l}92.5 \\
31\end{array}$ \\
\hline
\end{tabular}

Quality Measures

The plant lab will initially measure four quality attributes per container but eventually up to ten may be measures.

Usually, it is difficult to even rank the product according to overall quality when given multivariate data on product quality and attribute priorities. Exceptions would be when the product is on target or near specification boundaries over all attributes.

To facilitate comparison among containers and for input into the optimization, we have applied Taguchi quadratic loss functions (QLF). The QLF are typically used in Quality Assurance / Quality Control applications in estimating the deviation of a product's functional characteristics from its desired target value.

Consider the QLF

$$
L(y)=K(y-m)^{2}
$$

where $\mathrm{K}$ is some constant, $\mathrm{m}$ is the target, and $\mathrm{y}$ is the attribute value. 
The QLF (I) lends itself to mathematical manipulation. It measures closeness to target across the attributes. The points, i.e. assigned loss, are additive across containers, thus enabling the calculation of variability for a blend. Attribute priority and the amount of product in each container are also used in the calculations. The following considerations indicate why the QLF is an acceptable approximation in a wide variety of situations. Suppose the loss $L(y)$ depends only on the difference $y-m$. Let $L(y)=f(y-m)$, where $f$ is a non-negative function that $c$ an be differentiated at least twice and $f(0)=0$. If $f$ is expanded in a Taylor series through terms of second order, we obtain the approximation

$$
L(y)=f(y-m)=k 0+k 1(y-m)+k 2(y-m)^{2} .
$$

Terms of higher order are usually very small and can be ignored. The fact that $f(0)=0$ implies that $\mathrm{K} 0=0$ and the fact that $f$ is non-negative implies that $k 1=0$ and $k 2>0$. Thus the form of equation (2) reduces to equation (1). If there is more than one measurement, $y$, the average loss is

$$
\begin{aligned}
L & =E L(y) \\
& =K E\left(\frac{y-m}{2}\right)^{2} \\
& =K \operatorname{sig}
\end{aligned}
$$

where $\mathrm{E}$ is the expected value.

There are three types of QLF's.

* N-Type : The nominal (closest to target)-The best.

** S-Type : The smallest-The best.

*** B-Type : The bigger - The better.

\section{N-Type}

(a) Suppose the plus and minus specification limits $(m+-D)$ are equal to $D$, then the loss is defined as

$$
L(y)=P(y-m)^{2} / D^{2}
$$

\footnotetext{
where $P=$ Attribute Priority

$y=$ Attribute Value

$\mathrm{m}=$ Target value of $\mathrm{y}$.
} 


\section{OPTIMAL BLENDING QUALITY}

(b) Suppose the plus and minus limits are not equal, i.e., the upper spec $=m+D 1$ and the lower spec $=m-D 2$. Then the loss is defined as

$$
L(y)=P(y-m)^{2} / D 1^{2} \text { if } y<m
$$

or

$$
\mathrm{L}(\mathrm{y})=\mathrm{P}(\mathrm{y}-\mathrm{m})^{2} / \mathrm{D} 2^{2} \text { if } \mathrm{y}>\mathrm{m} \text {. }
$$

S-Type

Suppose the target $m=0$ and the upper specification is $D$. Then the loss is defined as

$$
L(y)=P y^{2} / D^{2} y>0
$$

The S-type QLF is a special case of the N-Type function.

B-Type

Suppose the target value $m=+$ infinity (ideal), the lower specification $=D$, and the attribute values $y>0$.

Let $z=1 / y$ in the S-Type function. Then $z>0$, the target $m=0$, the upper specification $=1 / D$ and

$$
L(y)=P D^{2} / y^{2} \text {. }
$$


Using the specifications in Table 1 , the loss functions for attributes $1,2,3$, and 4 are the following :

Attribute Con Spec Target Con QLF

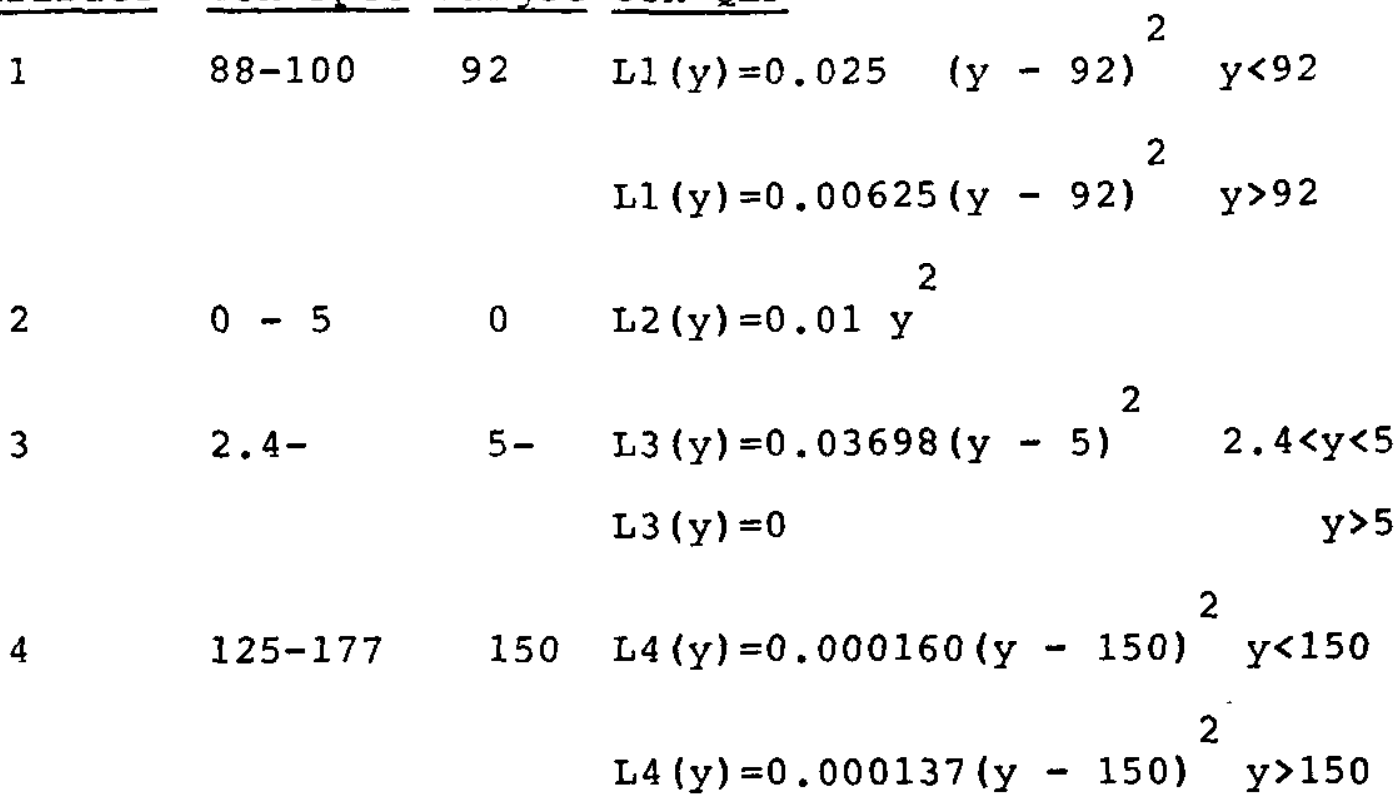

Similarly, blend optimization QLF's are formed from the specifications in Table 1. Plots of container quality points are shown in Exhibit 1 (attached). Notice that maximum points is obtained at boundaries of the specifications. There the points are equal to the attribute priority. If a container is on the specification boundary across all four attributes, then the maximum value of 1.0 is obtained. The minimum points of 0.0 is obtained when the product is on target across all four attributes.

\section{Optimization Criteria}

Potential blends have two associated statistics.

* The lot points which is sum across the points of the four calculated quality attributes for the blend.

* Average container points which is the weighted average of the container points. The weights are ecual to the amount of product in each container.

Both of these values are used in a performance statistic associated with each potential blend. The statistic is used in ranking blends with respect to the optimization criteria (e. g., blending from tails). 
The program enumerates all possible combinations of $4,5,6$, and 7 containers. From these combinations, an optimum is selected for each criteria. The maximum number of combinations when the storage area is full (36 containers) is given below.

\begin{tabular}{cr}
$\begin{array}{c}\text { Number of } \\
\text { containers }\end{array}$ & $\begin{array}{c}\text { Number of } \\
\text { combinations }\end{array}$ \\
\hline 4 & $\begin{array}{r}58,905 \\
5\end{array}$ \\
6 & $\begin{array}{r}1,947,992 \\
7\end{array}$ \\
\hline Total & $10,737,680$ \\
\hline & 1,369
\end{tabular}

The enumeration is done efficiently in the program. When the maximum blend product amount $(40.0)$ is reached for a certain combination of containers, additional containers are not considered. For example, if containers $1,3,10,14$ total max units of 40.0 , the program does not consider other combinations which include these four containers.

It is possible to develop ad hoc procedures for obtaining near optimal blends from a reduced number of combinations. However, a run time of 20 minutes for 36 containers on the Vax was considered, by the computer group, to be acceptable. The need for reducing CPU time may arise when the number of attributes is increased.

\section{Strategy 1}

- Identify blends closest to target using containers furthest from target.

(Blending from tails)

Each potential blend has an associated performance statistic, S1, which is a function of blend points (BP) and average (weighted) can points (ACP)

$$
S 1=B P+0.5 / A C P \text {. }
$$

The smaller $\mathrm{Sl}$ is, the more desirable the blend with respect to strategy 1 . We want the blend to be close to target, making BP near zero. In addition, if the containers are far from target, ACP will be large. Thus, the ratio $0.5 / A C P$ will be small. As such, $S 1$ precisely defines a trade-off between blend closeness to target and container variability. The 0.5 factor in SI was chosen on the basis of our judgement in observing the performance of the criteria on simulated data. It is a stringency factor in defining the trade-off between closeness to target and can variability. 
Strategy 2

- Identify blends closest to target using all combinations of containers.

(Center blending)

No restriction is placed on container variability. Therefore,

$$
S 2=B P \text {. }
$$

Using $\mathrm{s} 2$ as a basis of sorting potential blends, we will arrive closer to target, if possible, than using strategy 1. Blends from strategy 2 can be used for comparison with other strategies.

Strategy 3

- Identify blends with minimum can variability with consideration of the target. (Uniform Blending)

$$
S 3=0.60 \times A C P+0.40 \times B P
$$

Again a trade-off is offered between closeness to target and container variability. The can QLF's were used in computing BP so that $A C P$ and $B P$ are additive. However, we assign greater weight, 0.60 , to container variability than to blend closeness to target. The weights were selected on the basis of our judgement.

\section{Example of Calculated Values}

Suppose we are considering containers $2,4,12$, and 16 as a potential blend. These were selected from the 36 container example in the following section. The lab quality attributes and calculated values are summarized in Table 2 .

\begin{tabular}{|c|c|c|c|c|c|c|}
\hline \multirow[b]{2}{*}{ Id } & \multirow[b]{2}{*}{ Units } & \multicolumn{4}{|c|}{ Attribute } & \multirow{2}{*}{$\begin{array}{l}\text { Quality } \\
\text { Points }\end{array}$} \\
\hline & & 1 & 2 & 3 & 4 & \\
\hline $\begin{array}{r}2 \\
4 \\
12 \\
16\end{array}$ & $\begin{array}{r}9 \\
8 \\
9 \\
10\end{array}$ & $\begin{array}{l}92.04 \\
92.84 \\
92.21 \\
91.24\end{array}$ & $\begin{array}{l}0.80 \\
0.50 \\
1.70 \\
2.00\end{array}$ & $\begin{array}{l}4.13 \\
4.18 \\
4.75 \\
5.17\end{array}$ & $\begin{array}{l}160 \\
150 \\
160 \\
145\end{array}$ & $\begin{array}{l}0.048 \\
0.032 \\
0.045 \\
0.058\end{array}$ \\
\hline & 36 & 92.04 & 1.29 & 4.59 & 153. & 0.077 \\
\hline
\end{tabular}

Table 2 
To illustrate the calculation of container points, consider container 2. Its' quality points $(0.048)$ are calculated as in the following table.

Attribute

Points

1

$L 1(92.04)=0.00625(92.04-92)^{2}=0.00001$

2

$\mathrm{L} 2(0.80)=0.01(0.80)$

$=0.0064$

3

$L 3(4.13)=0.037(4.13-5)^{2}$

$=0.028$

4

L4 (160)

$=0.000137(160-150)$

2

$$
\text { Sum }=0.048
$$

Average container point is calculated as :

$$
\{0.048 \times 9+0.032 \times 8+0.045 \times 9+0.058 \times 10\} / 36=0.0465
$$

and is a index for quality.

The statistics for ranking this potential blend with other blends within each optimization criteria are

$$
\begin{aligned}
& \mathrm{S} 1=0.077+0.5 / 0.0465 \quad=10.830 \\
& \text { S2 } \\
& =0.077 \\
& s 3=0.60 \times 0.0465+0.40 \times 0.02465=0.038 \text {. }
\end{aligned}
$$

\section{Blending Example}

Consider the 36 container example in Table 3 . Optimal blends for each strategy are shown below.

\section{Strategy}

Container Number

S1

S2

53

$\begin{array}{rrrrr}3 & 17 & 19 & 32 & 33 \\ 13 & 16 & 17 & 26 & \\ 4 & 12 & 13 & 28 & \end{array}$


The optimal blend attributes estimates are

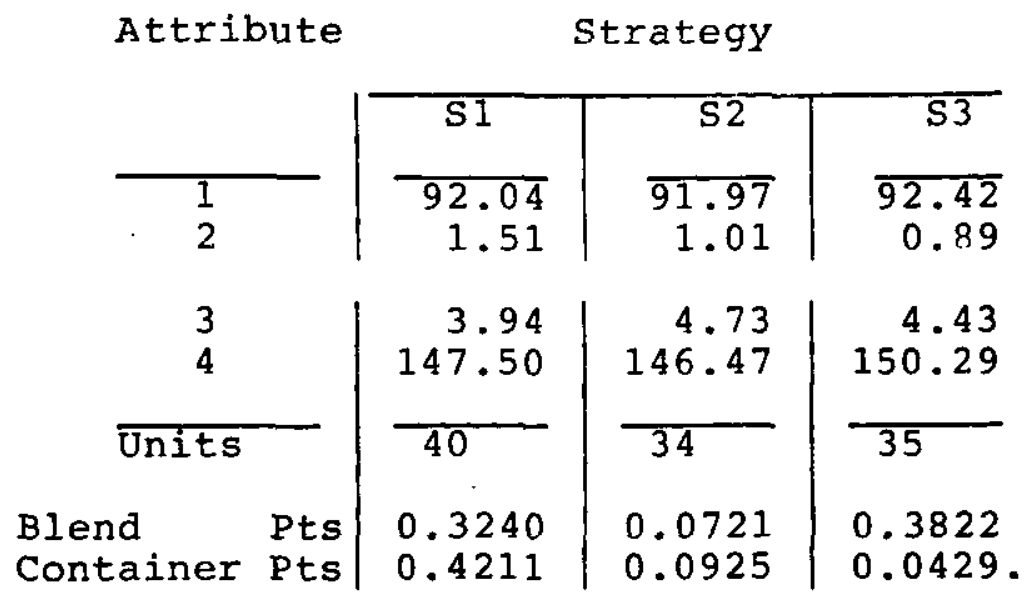

Consider the graphs in Exhibit 2 (attached) for container points. The distribution of the data are shown along the horizontal axis for each attribute (*'s). Also shown are the container attributes for optimal blends from Sl (circles) and s3 (squares). Notice the greater variability associated with $\mathbf{s} 1$ vis-a-vis s3 for, say, attribute 1. Recal1, s1 is blending from tails and $\mathrm{s} 3$ is uniform blending.

\section{Future Directions}

Future directions for this application could include:

- Blending containers not meeting specifications

- Simulation for the long run performance of the optimization criteria

- Probabilistic assessment of blend specifications

- Procedures for reducing CPU time. 

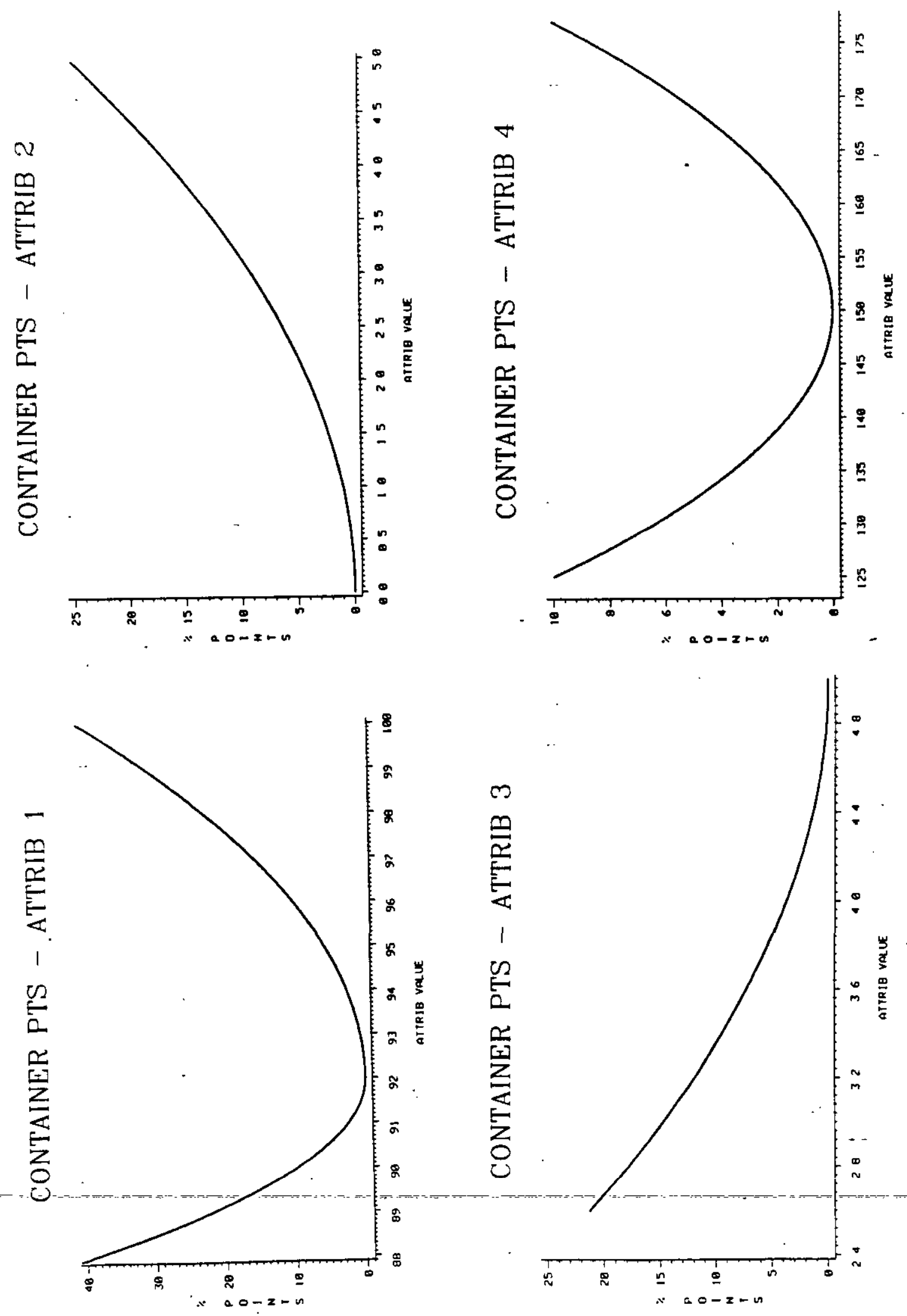

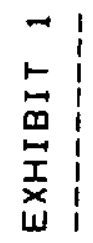

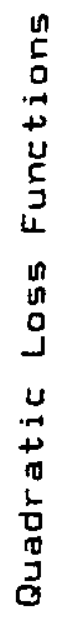




\section{Table 3}

36 Container Example with the Amount of Product (Units) and Quality Attributes.

\begin{tabular}{|c|c|c|c|c|c|}
\hline \multirow[b]{2}{*}{ ID } & \multirow[b]{2}{*}{ Units } & \multicolumn{4}{|c|}{ Attribute } \\
\hline & & 1 & 2 & 3 & 4 \\
\hline 1 & 10 & 88.39 & 5.00 & 2.40 & 147 \\
\hline 2 & 9 & 92.04 & 0.80 & 4.13 & 160 \\
\hline 3 & 8 & 89.46 & 0.47 & 3.09 & 140 \\
\hline 4 & 8 & 92.84 & 0.50 & 4.18 & 150 \\
\hline 5 & 6 & 96.49 & 5.00 & 2.86 & 160 \\
\hline 6 & 6 & 96.68 & 1.80 & 4.36 & 160 \\
\hline 7 & 10 & 97.01 & 2.40 & 3.33 & 150 \\
\hline 8 & 9 & 96.10 & 1.50 & 4.28 & 140 \\
\hline 9 & 8 & 94.87 & 3.20 & 3.98 & 160 \\
\hline 10 & 10 & 96.48 & 1.20 & 27 & 145 \\
\hline 11 & 10 & 90.05 & 0.60 & 2.40 & 147 \\
\hline 12 & 9 & 92.21 & 1.70 & 4.75 & 160 \\
\hline 13 & 8 & 90.92 & 0.50 & 32 & 140 \\
\hline 14 & 8 & 91.07 & 3.00 & 84 & 150 \\
\hline 15 & 6 & 92.59 & 3.00 & & 160 \\
\hline 16 & 10 & 91.24 & 2.00 & 17 & 145 \\
\hline 17 & 6 & 96.83 & 1.20 & 97 & 160 \\
\hline 18 & 10 & 97.61 & 2.20 & 6.05 & 150 \\
\hline 19 & 9 & 98.00 & 3.80 & 6.06 & 140 \\
\hline 20 & 8 & 94.02 & 4.11 & 5.69 & 160 \\
\hline 21 & 10 & 91.71 & 5.00 & 5.14 & 147 \\
\hline 22 & 9 & 92.19 & 4.68 & 4.27 & 160 \\
\hline 23 & 8 & 90.46 & 1.70 & 4.46 & 140 \\
\hline 24 & 8 & 92.01 & 1.70 & 3.57 & 150 \\
\hline 25 & 6 & 93.20 & 1.60 & 4.67 & 160 \\
\hline 26 & 10 & 90.63 & 0.30 & 86 & 145 \\
\hline 27 & 6 & 91.87 & 1.10 & 3.92 & 160 \\
\hline 28 & 10 & 93.48 & 0.80 & 4.43 & 150 \\
\hline 29 & 9 & 94.28 & 1.00 & 08 & 140 \\
\hline 30 & 8 & 95.16 & 0.60 & & 160 \\
\hline 31 & 10 & 94.94 & 0.70 & 4.84 & 147 \\
\hline 32 & 9 & 88.67 & 1.50 & 2.60 & 160 \\
\hline 33 & 8 & 88.16 & 0.20 & 2.40 & 140 \\
\hline 34 & 6 & 95.98 & 2.00 & 5.00 & 150 \\
\hline 3 & 8 & 96.01 & 1.10 & 5.01 & 160 \\
\hline 36 & 10 & 96.79 & 1.20 & 4.03 & 145 \\
\hline
\end{tabular}




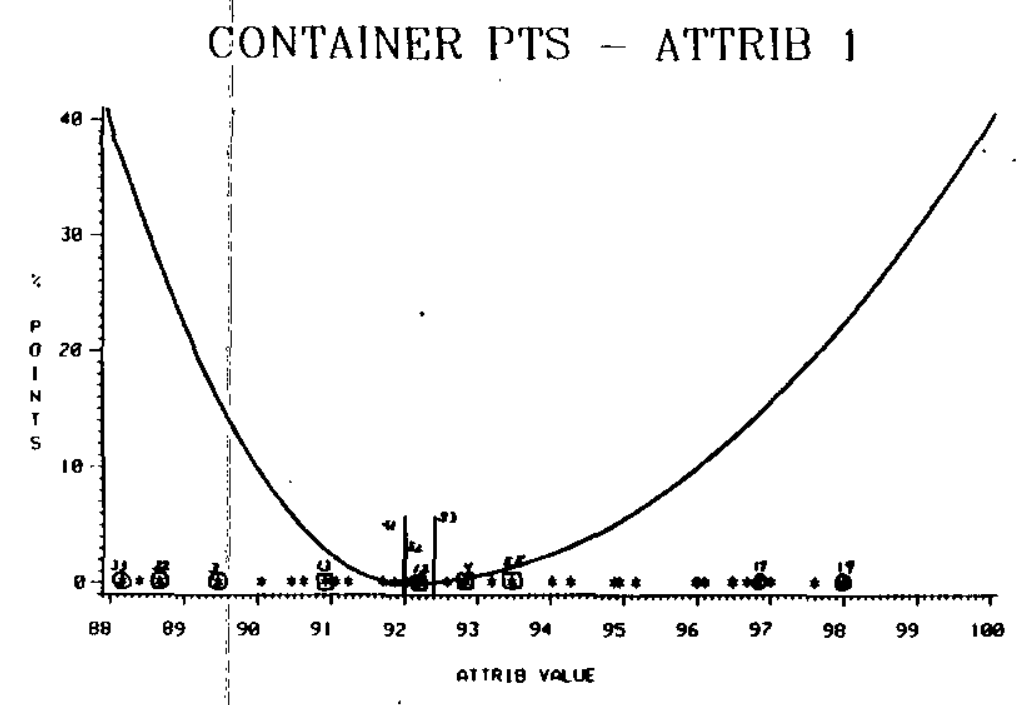

CONTAINER PTS - ATTRIB 2
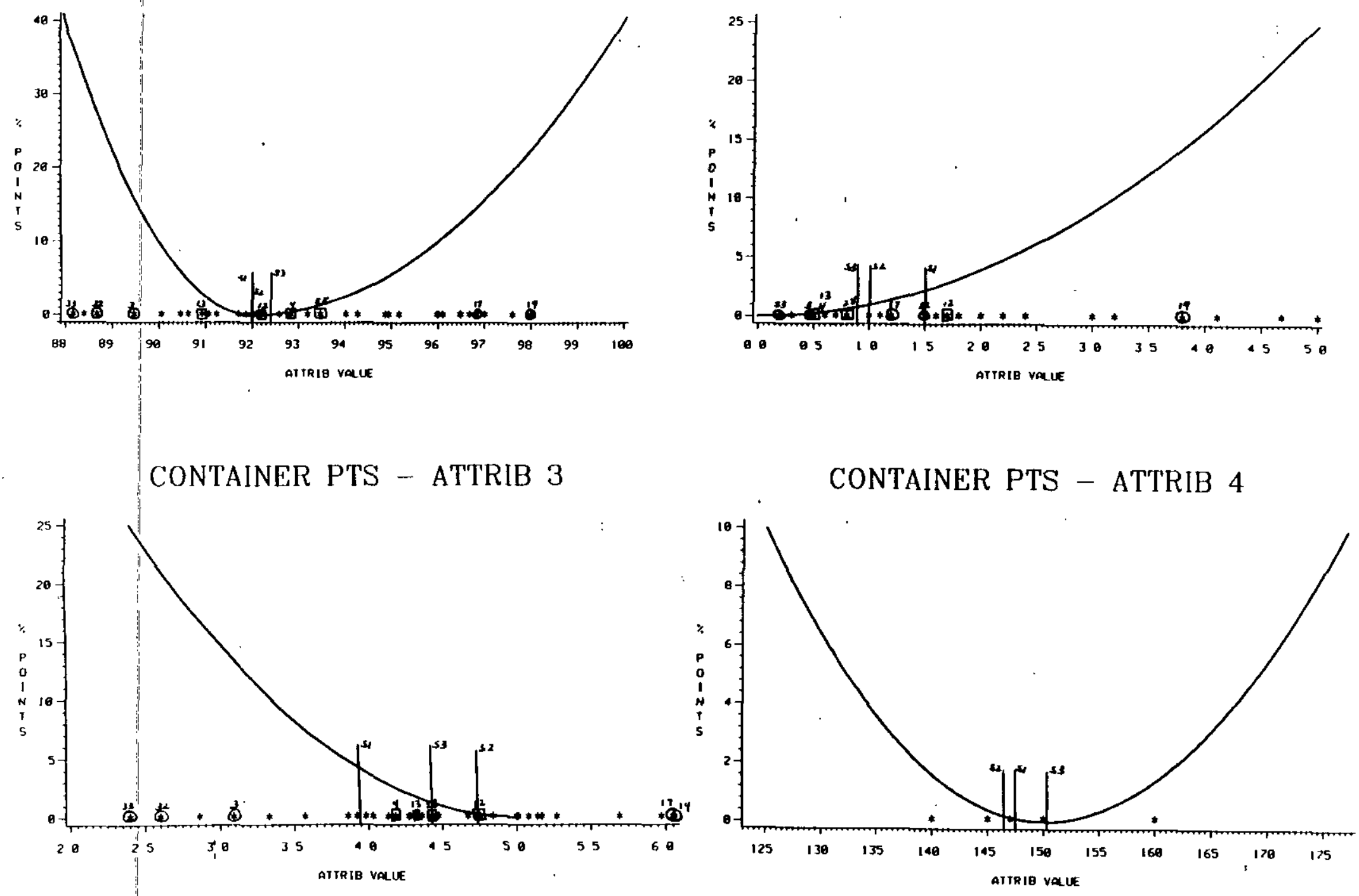

EXHIBIT 2

36 Can Example 